\title{
La Violencia del Lugar
}

\section{Violence of Site}

\author{
Zulema Moret \\ Grand Valley State University \\ moretz@gvsu.edu
}

Resumen - Este ensayo presenta personajes nómades, huérfanos, habitantes de la noche, sin hogar y sin ley. Estos personajes nos permiten analizar las relaciones entre violencia y lugar, en la cultura argentina durante los noventa y el inicio del 2000. Las películas elegidas son Un día de suerte (2002) de Sandra Gugliotta, Vagón Fumador (2001) de Verónica Chen y Hoy y Mañana (2003) de Alejandro Chomski. Las tres películas, filmadas a principios del 2000, tienen como escenario la ciudad de Buenos Aires, las historias siguen los desplazamientos de los jóvenes protagonistas por la ciudad, estableciendo nuevas fronteras entre el centro y la periferia, y la noción de no-lugar en la cartografía de la ciudad de Buenos Aires.

Palabras clave: Violencia, prostitución, juventud, crisis económica, centro/periferia, no-lugar.

Abstract - This essay introduces nomadic characters, orphans, night crawlers, jobless and lawless people. These characters will allow us to analyze the bonds between violence and site in Argentine culture during the nineties and at the beginning of our century. The chosen films are Un dia de suerte (A Lucky Day, 2002) by Sandra Gugliotta, Vagón Fumador (Smoking Car, 2001) by Verónica Chen, and Hoy y Mañana (Today and Tomorrow, 2003) by Alejandro Chomski. These three movies, filmed at the beginning of the year 2000, are set in the city of Buenos Aires; the stories follow the wanderings of their young protagonists, showing new displacements between center and periphery in Buenos Aires' cartography.

Keywords: Violence, prostitution, youth, economic crisis, center/periphery, noplace. 
La urbe programada para funcionar, diseñada en cuadrícula se desborda y se multiplica en ficciones individuales y colectivas (107)

Nestor García Canclini

Imaginarios urbanos

«La ciudad es como un pulpo»

Reny, en Vagón Fumador

Nómades, huérfanos, gente de la calle, habitantes de la noche, sin trabajo y sin ley...

Estas son algunas de las características de los jóvenes protagonistas de las tres películas elegidas para hablar de la violencia en la cultura argentina durante los noventa y al inicio de este siglo. Me voy a referir a Un día de suerte (2002) de Sandra Gugliotta, Vagón Fumador (2001) de Verónica Chen y Hoy y mañana (2000) de Alejandro Chomski. Las tres películas, filmadas a principios del 2000, se ubican en la ciudad de Buenos Aires, y sus historias siguen los recorridos de sus protagonistas. Los temas y aproximaciones son representativas del denominado nuevo cine latinoamericano, una corriente que se hizo notar durante los noventa y cuya influencia continúa durante esta primera década, bajo los efectos de la cultura urbana globalizada, frente a la desarticulación del poder político y el sentimiento de pérdida de la comunidad. Este discurso ha recibido, asimismo, y sobre todo en el ámbito de la literatura, el nombre de «realismo sucio» (Dirty Realism) y se refiere a un cine que cuestiona la vida en las grandes ciudades, la corrupción de los valores, la crisis de identidad, la marginalidad y la extrema pobreza (Christian León, 3). Aunque el denominado Nuevo Cine argentino se diferencia del Realismo Sucio, no se encuentra exento de dichos tratamientos y enfoques que muestran la crisis de los noventa, tratando la violencia urbana, la marginalidad social y la identidad quebrada. Una de las características más importantes del Nuevo Cine argentino consiste precisamente en su tratamiento visual del espacio, tanto en las grandes urbes como en las periferias, o en el tratamiento de los desplazamientos o interacciones entre periferia y centro. Como bien apunta Sergio Woolf en su ensayo «La Estética del Nuevo Cine Argentino: el Mapa es el Territorio", los directores que ofician de pioneros de este nuevo movimiento intentan una nueva lectura de los lugares menos conocidos de Buenos Aires, y un retorno a los espacios periféricos (2).

A lo largo de este ensayo, intentaré enfocar el concepto de espacio como complementario de la construcción de algunos personajes principales como un marco a través del cual la violencia del lugar puede llegar a percibirse aun cuando ellos merodeen las ciudades y las zonas del centro de la ciudad. Edward Casey aborda esta relación en su análisis fenomenológico de la construcción del lugar: «Bodies and places are connatural terms. They interminate each other. [...] Places also gather experiences and histories, even languages and thoughts» (25). A partir de estos conceptos, vamos a explorar cómo se define el espacio en la interacción entre los personajes de estas tres películas y la ciudad de Buenos Aires. Los protagonistas de estas los filmes: Vagón Fumador, Un día de suerte y Hoy y mañana, son habitantes urbanos, y en algunos casos, como en Un día de suerte, Elsa y sus amigos se desplazan a las zonas periféricas para el tráfico ilegal de drogas mediante el uso de recetas ilegales, estableciendo fronteras movibles entre centro y periferia y borrando los límites territoriales movidos por la supervivencia. Vagón Fumador constituye una historia compleja y se centra en dos paseantes nocturnos: Reny, cantante en una banda, 
quien vive sola, y Andrés, un joven que vive de la prostitución callejera por la Plaza San Martín y por los cajeros de la calle Lavalle y sus alrededores. Podemos fácilmente reconocer la violencia que se genera en estos encuentros sexuales en los lugares públicos. El caso de Paula, la protagonista de Hoy y mañana, saca a la luz la complejidad de la relación entre mercancía e identidad, porque ella elige prostituirse durante una noche para poder pagar el alquiler de un apartamento estudio, ubicado en una zona céntrica, no marginal. Su acción pone en evidencia, de algún modo, el nivel de desolación en el que se encuentran estos personajes, quienes, como errantes nocturnos, están expuestos a toda clase de situaciones de violencia en su vida cotidiana, en sus interacciones personales y sociales.

La ciudad de Buenos Aires es el escenario en el que estos tres filmes establecen una estrecha asociación entre el tema de la violencia, la construcción de género y su interacción con las clases sociales. Como observa Christian León: «Frente a la actual pérdida de legitimidad la sociedad letrada que sostiene la identidad nacional, elabora códigos mestizos que reincorpora elementos de la cultura global de Occidente, y de los imaginarios locales. Muestra la cultura callejera como un espacio híbrido donde confluye el efecto desterritorializador del imaginario mediático y la reterritorialización por el mundo marginal a partir de sus códigos subalternos» (31).

La ciudad representa una fuerza activa en el conjunto de los cuerpos y lazos sociales. Elizabeth Grosz en su ensayo «Bodies-Cities» [Cuerpos-Ciudades] describe un conjunto de efectos generales en aquellos que viven en dichas ciudades. Ella concluye en que la ciudad deja siempre sus huellas en la corporalidad del sujeto, y como un resultado de esta interacción se produce una revolución que también dejará sus marcas y que también reflejará el avance de la tecnología que conducen a afirmaciones como las siguientes: «the subject's body will no longer be disjointedly connected to random others and objects through the city's spatiotemporal layout; it will interface with the computer, forming part of an information machine in which the body's limbs and organs will become interchangeable parts.» (387). Como resultado de estas huellas que la ciudad deja sobre sus habitantes, sabemos que ciudad es una construcción polisémica. Las ciudades no son ni inocentes ni culpables por las acciones que provocan, su escenario, su desarrollo, su movimiento interno causan todo tipo de cambios en las vidas de sus habitantes; la ciudad es la misma, pero y al mismo tiempo parece diferente, porque como indica más adelante Grosz: «The city's form and structure provides the context in which social rules and expectations are internalized or habituated in order to ensure social conformity or, failing this, position social marginality at a safe distance (ghettoization), and this fact means that the city must be seen as the most immediate locus for the production and circulation of power.» (386). Por ejemplo, en una escena de Vagón Fumador, Reny y Andrés están sentados afuera, sobre el techo de un rascacielos, mirando Buenos Aires y Reny le dice a Andrés: «La ciudad es un monstruo, te fuerza a comprar cosas, a consumir [...]; ellos no ven al monstruo, la brutalidad, en pedazos, parte por parte» (Chen, Vagon fumador). Esta escena cargada de poesía de una pareja mirando la ciudad desde la terraza de un rascacielos durante la noche, no es la misma imagen con la que se representa la ciudad que aparece en Un día de suerte, donde los piqueteros o manifestantes en las asambleas populares públicas llenan el espacio de gritos, mientras el ruido de los helicópteros que vuelan sobre la ciudad, las discusiones de los vecinos durante la asamblea, los lejanos sonidos de los disparos. La ciudad de Un día de suerte es la ciudad sitiada, bajo el efecto 
de los cortes de electricidad en las zonas del sur de la ciudad, que ocurrieron en Buenos Aires en el mismo año en que se filmó la película.

La ciudad y sus prácticas cotidianas, el trabajo, el entretenimiento, el uso de drogas, atrae y también repele a sus paseantes. Los negocios de la noche, los hoteles y las zonas de paseo son lugares a los que la gente joven va para intercambiar productos y servicios. El diálogo entre Reny y Andrés detrás del escaparate de una pizzería que bien podría estar en la calle Lavalle o en cualquiera otra del centro de la ciudad son un buen ejemplo de ello. Al referirse a sus orígenes y a los lugares a los cuales pertenecen, dicen: «Estamos viajando a la velocidad de la luz» Más tarde, mientras comen pizza, agregan: «La pizzería es una nave espacial» y «Lavalle es la galaxia de al lado» (Chen, Vagon fumador). Vagón Fumador construye una ciudad con fragmentos que reflejan a sus individuos, las calles, las luces, los espejos y las criaturas se reflejan duplicadas en los escaparates de las tiendas. No hay centro, no hay mapa; la ciudad se construye fragmentariamente, produciendo un constante intercambio imaginario con sus habitantes. Los juegos que se juegan en la noche establecen una relación irónica con los desplazamientos y juegos que llevan a cabo los jóvenes en sus patinetas (roller skates) alrededor del monumento del Libertador, construido en memoria de su héroe nacional, José de San Martín. Otra referencia irónica con relación al valor de los monumentos nacionales que, se supone, representan la $\mathrm{Na}$ ción, se localiza en la escena en la que Elsa se reúne con sus amigos. Ellos están jugando alrededor de los monumentos y uno de ellos comienza a imitar la voz del Papa o de un sacerdote leyendo en italiano un texto sobre Italia y de algún modo sus movimientos desmitifican la importancia de las figuras autoritarias como en la escena en torno a San Martín, el «Padre de la Patria», y las escenas profanas en torno al Papa.

Los juegos urbanos, las realidades fragmentarias que forman parte de la maquinaria de cada día en el primer mundo se desplazan y muestran su influencia en algunas escenas de Vagón Fumador. Los cajeros automáticos, los móviles, las máquinas de juego son signos de la ciudad nocturna y parecen complementar, como si fueran una prótesis, el silencio impuesto por la falta de comunicación entre la gente que circula por ella. Las fronteras entre centro y periferia se disuelven. En Un día de suerte un grupo de gente joven se reúne a fumar marihuana a una zona periférica, donde imagina vacas que luego se desplazan a la zona del centro y de algún modo funcionan como puente simbólico entre las dos zonas, en tanto las vacas van a reaparecer caminando por las calles de la ciudad y por los vecindarios de la periferia de la ciudad.

Los traficantes de drogas desplazan a partir de su acción las fronteras entre la zona ilegal y la legal, la frontera entre la práctica legal e ilegal, entre acciones prohibidas y permitidas. Elsa y sus amigos trabajan en la ciudad, en trabajos temporales, reparten panfletos, pósters, hacen publicidad de productos sin valor para el consumo social, o en su tiempo libre, que venden mercancía que han conseguido mediante el contrabando, constituyendo, así, una red de jóvenes que ha descubierto cómo sobrevivir en una gran ciudad. Desde esta perspectiva, Marc Hatzfeld en su análisis de los vecindarios franceses explica: «Los barrios o los clanes de barrio ofrecen, cada cual, especialidades diversas, de modo que, en ese universo un tanto paralelo pero tolerado en gran medida, la clientela enterada sabe adónde dirigirse y a quién para tal producto o servicios. Garajes, apartamentos o parking sirven de talleres, el sistema de tontine hace a menudo de banco pirata y salen de las sombras jerarquías ocultas al nivel de redes» (59). 
Buenos Aires es el espacio en el que los protagonistas llevan a cabo sus transacciones vitales. Los interiores de las casas, los bares y las cafeterías muestran el deterioro progresivo de sus condiciones de vida: paredes despintadas, casas destruidas, vecindarios vacíos que vistos desde arriba provocan gran angustia. Ninguna de estas películas se detiene en interiores; durante la mayor parte del tiempo, los personajes cruzan la ciudad buscando algo que parece perdido, o que no puede encontrarse. De este modo, reconocemos las calles del centro y también algunas que se extienden hasta las zonas suburbanas.

Dentro de este entramado espacial existe otra categoría a tener en cuenta, la de «nolugar», enfatizada en Vagón Fumador como lugares alternativos en donde los personajes pueden pasar su tiempo de ocio o ganar algún dinero mediante el intercambio sexual. En su antropológica lectura de la ciudad, Marc Augé define los «no-lugares» como espacios de circulación, distribución y comunicación contemporáneos. Los aeropuertos, las estaciones de gasolina, las galerías y centros comerciales son «no-lugares", como asimismo los cajeros automáticos, o las máquinas de venta de billetes de transporte. Estas máquinas permanecen mudas en el intercambio que el sujeto establece con ellas, y en general, todo tipo de redes que con la ayuda eventual de satélites traen imágenes o información a un grupo particular de individuos son considerados «no-lugares» (Augé, 28).

Parte de la diégesis en Vagón Fumador tiene lugar en cajeros, máquinas, barras de bares, pasillos, escaparates, esquinas de teatros y cines, parques, y otras áreas de paso, durante la noche, en el lugar en el que los personajes pierden sus identidades móviles.

La cámara se utiliza en un intento por captar la fragmentaria cualidad de la realidad y enfatiza, de algún modo, dicha movilidad mediante el corte de cabezas, ojos, caras y gestos. Un tratamiento poético de la noche expresa la desorientación de los personajes a la búsqueda de clientes o de su grupo de amigos. Al respecto, Luciano Monteagudo, escribe en una reseña del film:

Hay una apropiación de la ciudad que es muy particular en Vagón Fumador [...] Difícilmente la elegante Plaza San Martín sea parte del circuito de oferta sexual de Buenos Aires, pero el film la convierte en el lugar de reunión de Andrés y de sus amigos y clientes, un aquelarre de taxi-boys aullando frente al Círculo Militar y alrededor del Monumento al Libertador. Esa vampirización de la ciudad (hay algo profundamente nocturno en el film de Chen) le da un valor de extrañamiento. [...] Con el acompañamiento de un excelente diseño sonoro de Edgardo Rudnitsky, la cámara — como si se hubiera subido a los rollers de Andrés- va atravesando en ralenti las calles y se detiene en la textura de un rostro o en la dinámica de un gesto, capaces de enriquecer el paisaje de neón (Monteagudo, 1).

Algunos lugares vacíos de vida humana, como la piscina donde los personajes nadan y juegan en el agua, o el vagón, al final de la película, expresan sus vidas solitarias, las desvastaciones que han sufrido y la futilidad de las palabras.

Andrés y Reny envían mensajes mediante sus móviles, van a los cajeros y Reny establece una mirada de complicidad con la audiencia, como voyeurs cómplices, cuando Andrés mantiene encuentros sexuales en los cajeros. Por eso, el «no-lugar» es el lugar de los otros, pero sin su presencia, el lugar transformado en espectáculo, un espectáculo en su propio derecho atrapado en palabras (Augé, 2).

Este «otro» de Augé no es el de las postales o anuncios turísticos, sino el desempleado, el huérfano, el que no tiene raíces ni hogar, el inmigrante, el sin hogar, buscando un lugar en donde vivir y en donde cumplir sus deseos. 
Podemos extender perfectamente esta definición a los escaparates de la calle por la que circula Paula, la protagonista de Hoy y Mañana. Paula es actriz, pero interpreta otro rol para ganarse la vida durante una noche y poder pagar sus deudas. La actuación (performance) de Paula se ubica en un cierto tipo de escaparate que se encuentra en los bordes con la categoría de «no-lugar», puesto que de su condición de sujeto pasa a ser objeto de consumo, como Andrés, por una cierta cantidad de dinero que forma parte de la transacción comercial, sostenida por los cuerpos y el sexo. Sin embargo, esta interacción permanente entre los jóvenes protagonistas y la ciudad constituye una relación conflictiva, enmarcada por la violencia que cruza la ciudad y su historia. La violencia del lugar tal como aparece en estas películas es una mancha repentina en la narrativa visual que deja una especie de mancha que se vuelve más complejo de definir, porque constituye opacidades de significación en el conjunto del discurso. Coincidimos en este punto con Christian León en su análisis de las películas del director colombiano Víctor Gaviria, cuando relaciona algunos efectos fuera de lugar de estos films con el traumático encuentro con «lo Real».

Entendido a partir de términos lacanianos: «Lo real puede representarse por el accidente, el ruidito, ese poco-de-realidad que da fe de que no soñamos [...] esa realidad no es poca cosa, pues nos despierta a otra realidad escondida tras la falta de lo que hace las veces de representación» (Lacan, 68). Lo que llamamos una mancha es más precisamente un agujero, el vacío. Las películas elegidas para este ensayo brindan un claro testimonio de este agujero o vacío, apuntando a la falta y a la presencia de la realidad y constituyendo una forma de violencia en cada una de las representaciones aludidas.

Tal como he sugerido anteriormente, en el caso de los films argentinos analizados en este ensayo, el tipo de violencia se relaciona con los acontecimientos históricos que ocurrieron en la ciudad durante el «crash» económico del 2000 y no tiene un referente explícito; se encuentra y se reconoce en situaciones en las que los personajes se mueven, en algunos casos, sin palabras; el estado silencioso de la violencia atraviesa la vida de los protagonistas. Ellos sienten las consecuencias que la violencia social inflige sobre sus vidas y no pueden escapar de ella; por ejemplo, Paula, la joven protagonista de Hoy y Mañana de Alejandro Chomski, no puede pagar el alquiler de su estudio, no puede encontrar un trabajo y su padre no le quiere prestar dinero para pagar sus necesidades básicas. Entonces, decide salir y trabajar como prostituta en la calle. Ella se siente libre de elegir esta acción, pero dicha acción, al mismo tiempo, la sumerge en un estado de desolación total, sin el más mínimo soporte con relación a su vida. Cuando le grita al cliente «no soy una puta», le dice la verdad: ella no es una puta. Ella tiene que «venderse» para pagar la renta del alquiler, ella tiene que actuar, tiene que representar un «personaje». Ella hace el único trabajo que pudo encontrar para solucionar un conflicto importante en ese momento de su vida.

La violencia se refleja en la ciudad porque los acontecimientos dejan su huella en el cuerpo social. Por ejemplo, si aludimos a la falta de empleo de la sociedad argentina, este es un hecho político que impone sus consecuencias en la vida de los jóvenes protagonistas. Cuando Elsa, la protagonista central de Un día de suerte busca un trabajo para poder ahorrar dinero para viajar a Italia, los piqueteros o huelguistas aparecen en una manifestación en las calles de la ciudad y no podemos ignorar estos acontecimientos que aparecen como telón al desplazamiento de Elsa por las zonas del centro de la ciudad porque «the newly impoverished sector's relationship to politics and collective action 
has also been transformed. [...] Then, following the events of December 2001, the impoverished middle class, no longer ashamed, took to the streets forming neighborhood assemblies and pressure groups made up of people whose savings had been frozen and then devalued in the banks» (Grimson, Kessler, 99) ${ }^{1}$.

Al mirar estas películas recientes, el espectador establece un puente entre las acciones políticas que rodean la historia principal y los personajes que muestran el panorama devastador de la sociedad y sus efectos sobre el individuo, quien aparece en su condición de imposibilidad por construir su futuro. La violencia que la ciudad impone a las vidas de sus habitantes se extiende a otros territorios de la vida diaria. En la escena final de Hoy y Mañana, Paula decide dar por terminado su servicio a un cliente que ya le había pagado, y mientras ellos se encuentran en la habitación del hotel, la pantalla del televisor muestra las escenas de un documental con animales donde un tigre come a una presa menor. Es evidente que la relación entre lo que se despliega en la pantalla guarda relación semántica o crea analogías con lo que está ocurriendo en ese momento en el cuarto de la habitación, donde Paula rechaza ser víctima de la penetración anal y le grita al hombre: «No soy una puta», en su desesperación. ${ }^{2}$

Otro interrogante en torno a estos jóvenes y sus familias es el que concierne a qué función cumple la familia, y qué tipo de familia aparece representada. En un primer momento resulta fácil reconocer que la familia es una ausencia, parecen huérfanos deambulando por una ciudad a la búsqueda de un futuro inexistente.

Sabemos que la postmodernidad se estructura en torno a la caída [o falta] de un padre como una construcción social y simbólica. De hecho el colapso económico que Argentina sufrió muestra los efectos devastadores del sistema en el cuerpo familiar. Entre las tres películas elegidas para este análisis, es en Un día de suerte en donde aparece lo que podríamos denominar «el discurso familiar», en tanto es la única en donde reconocemos

Judith Filc al referirse a las consecuencias de la política de Menem en la sociedad argentina, señala lo siguiente: «Estas transformaciones tuvieron como consecuencia la fragmentación de las clases medias (con la división consiguiente en (ganadores) y (perdedores)) y con la crisis de identidad consiguiente para los llamados «nuevos pobres`. Esta crisis identitaria, asimismo, atravesó las diferencias de clase. La precarización laboral afectó la construcción de identidad en los sectores populares, cimentada en el pasado en los derechos adquiridos durante el primer gobierno de Perón. La pérdida de los derechos sociales que en la Argentina habían estado asociados tradicionalmente a la condición del strabajador`, la desaparición de espacios de asociación ligados al lugar de trabajo, la pérdida de representatividad de las instituciones tradicionales, todos estos fenómenos se conjugaron para llevar a lo que los diversos autores describen como el debilitamiento del lazo social» (183-184).

2 La explicación de Jean Baudrillard sobre al menos dos tipos distintos de violencia sirve para corroborar su interpretación de la escena y explica parte de la diferencia del siguiente modo: «La violencia tradicional es mucho más entusiasta y se halla vinculada a los sacrificios rituales. La nuestra es una violencia simulada en el sentido en que, más que de la pasión o del instinto, surge de la pantalla y en los media que fingen grabarla y difundirla, pero que en realidad la preceden y la estimulan» (Baudrillard, 107).

Sin embargo, existe otro tipo de violencia más allá de lo virtual, que se aplica perfectamente a parte de la estrategia discursiva en el nuevo cine latinoamericano y en particular al cine argentino. De acuerdo con Baudrillard: «Podemos distinguir una forma primaria de violencia: la de la agresión, la opresión, la violación, la relación de fuerzas, la humillación, la expoliación, la violencia unilateral del más fuerte. A la cual puede responderse con una violencia contradictoria: violencia histórica, violencia crítica, violencia de lo negativo. [...] Son éstas, formas de una violencia determinada, con un origen y un final, cuyas causas y efectos son localizables y corresponden a una trascendencia, ya sea del poder, de la historia o del sentido» (108). Adecuados ejemplos de este tipo de violencia son los films colombianos y mexicanos respectivamente Amores Perros, La vendedora de rosas, Rodrigo D y Mundo Grúa, Bolivia, El cielito y El bonaerense, en Argentina. 
las relaciones interfiliales y la presencia de la «historia» familiar en intersección con la historia local y la genealogía.

La familia que se nos presenta en esta película responde a algunos de los parámetros comunes de esa época: padre desempleado, una madre cocinando para otras personas, un abuelo anarquista, que recuerda todavía. Elsa les expresa sus emociones, se enamora, desea viajar y escapar de esa realidad, y trata de conseguir el dinero necesario para ello. Walter, el novio de Elsa, comprende su deseo de irse y la apoya, brindándole algún dinero para que pueda viajar. Elsa es la única protagonista con una familia y una «historia social, política» detrás; ella también es la única protagonista que, equivocada o no, llega a cumplir sus sueños, a la búsqueda de la felicidad; no en vano, la escena final de la película nos muestra a la joven arrojando una moneda a la Fontana de Trevi. El abuelo italiano de Un día de suerte es el único que establece una conexión con su nieta Elsa, una conexión que reestablece una suerte de "geográfico balance» con la historia del abuelo inmigrante, un anarquista italiano quien llegó a la Argentina «a hacer la América». Así, el territorio del abuelo italiano es el territorio de la evocación y el compromiso político cuyo discurso contamina hasta cierto grado el discurso de Elsa, lleno de aporías.

Los universos de los personajes en Vagón Fumador y en Hoy y mañana habitan desoladas zonas, donde nadie ayuda a nadie: en el caso de Paula, su distante padre rechaza ayudarla en una situación de gran dificultad; en el caso de Reny «no hay familia, nací de un tubo, soy el resultado de un experimento genético» y cuando Andrés le pregunta, «¿y qué pasa con la gente de la banda?», ella le responde: «tubos de ensayo». La ausencia de genealogía y de estrechos lazos muestra la fragmentación del sujeto postmoderno, arrojado al mapa de la ciudad con diferentes deseos inscriptos en sus cuerpos y fantasías.

Perdidos en la gran ciudad, perdidos en la red social de relaciones, perdidos en el centro del conflicto, los personajes de algunas de estas películas son huérfanos en la búsqueda de algo que pueda darle una respuesta a la desesperación y a la falta de esperanza, algo «real» como en el caso de Reny. De maneras parecidas y bajo diferentes circunstancias estos personajes recrean a aquellos huérfanos de las novelas escritas a principios del siglo veinte, en la búsqueda de una identidad y una libertad personal, fuera de la familia, o sin familia, puesto que el núcleo familiar ya no opera como lugar de seguridad y verdad. Ellos disponen de su libertad, pero no pueden sostenerla por un entorno económico desfavorable y la falta de trabajo y estabilidad en sus vidas.

Las situaciones vinculadas al género son muy relevantes en estas historias y con relación al comportamiento de los personajes principales. Aunque se expresen con diferentes intensidades en las películas, las protagonistas ya no son una proyección del deseo masculino y no logran clasificarse en categorías binarias: santa o prostituta, ángel o demonio. Las mujeres se han convertido en el símbolo de un universo descompuesto socialmente donde las polaridades genéricas desaparecen, y la experiencia de la calle disloca los lugares tradicionales adjudicados a la construcción femenina. Los roles genéricos han sido deconstruidos en la representación de los sujetos femeninos; las figuras masculinas son necesarias pero no son indispensables; los cuerpos femeninos funcionan como mercadería que puede venderse o comprarse para conseguir el dinero mientras que los cuerpos masculinos son objeto de similares transacciones. Cada persona tiene un precio que debe conocer para poder disfrutar y por lo tanto, cada uno debe ponerse un precio, de acuerdo con Andrés, el «taxi boy» en Vagón Fumador. Por el contario, Reny, la protagonista, ignora su precio y las relaciones que establece con otras personas responden 
al deseo de sentir que «algo real» marca su vida. Reny no desea enamorarse, ella quiere «sentir», podríamos interpretar que Reny busca algo que pueda darle sentido a su vida y llenar este vacío.

Los jóvenes protagonistas de las películas seleccionadas rechazan sentirse involucrados emocionalmente con otra gente, hablar sobre sus emociones, por eso se explica que los gritos, llantos, risas, y fórmulas coloquiales fijas como argots o pertenecientes a grupos se escuchen como una forma de "proto-lenguaje»" No hay palabra para el amor, no hay discurso que posibilite el amor. Lo más lejos que llegan los personajes es a ofrecer sus cuerpos para obtener un beneficio imposible de alcanzar de otro modo. Los métodos elegidos por Paula para pagar su alquiler son un fracaso, el viaje de Elsa a Italia termina siendo un tremendo error, en tanto no encuentra al italiano que conociera en la Argentina; los encuentros causales de Reny con Andrés terminan en fracaso. El duelo es la maquinaria que ubica la soledad en el centro del escenario, volviendo a introducir algunos aspectos formales que nos recuerdan la Nouvelle Vague francesa de los cincuenta o algunos protagonistas del cine argentino de los sesenta, capturados en una zona de grandes dudas. ${ }^{4}$

Todos estos jóvenes desean marcharse, irse lejos —es el caso de Elsa, Reny y Andrésy por eso, siguiendo sus deseos, experimentan con los límites que no se han establecido en el proceso de establecer los lazos sociales. Si necesitan comer y no disponen de dinero, roban del supermercado o se prostituyen. Ellos no establecen «relaciones». No hay lenguaje para hablar del amor, el dolor, la necesidad, la realidad o la rabia que los fracasos cotidianos provocan en sus vidas. ${ }^{5}$

Sin embargo, algunos de estos personajes evidencian un progresivo crecimiento en su capacidad de sentir a medida que la historia se despliega ante nuestros ojos, o parecen ser conscientes de su situación presente. Paula llora en la costanera, frente al río, después de las humillaciones sufridas como prostituta; ella llora como no pudo llorar antes. Ella necesitaba tocar fondo, caer en situaciones degradantes como mujer para poder llorar por la falta, la ausencia de amor, sostén, y para no aceptar, finalmente, el contrato que implica un intercambio de mercancía, en tanto ella no es una "prostituta» sino una mujer que necesita representar este papel para poder sobrevivir. Paula no ha aprendido lo que Linda Carpenter nos recuerda como un importante acuerdo entre la prostituta y su clien-

3 Sobre el intercambio dialógico entre los personajes de Un día de suerte, Rodrigo Seijas opina lo siguiente: «Son los momentos de rutina y aletargamiento entre amigos los que adquieren mayor vuelo en este film: las conversaciones y bromas sin sentido alguno, la fumata de porros, las escenas íntimas entre Mirás y Bassi (más allá de que los dos atraen al público femenino y masculino respectivamente). En cambio, los tramos con marcada «carga ideológica) recuerdan los antiguos vicios declamatorios del cine argentino» (Un dia de suerte. Cineismo. Sitio Web. Fecha de ingreso: julio 27, 2007).

4 Gonzalo Aguilar explica: «En 1953 los jóvenes que después formarían la Nouvelle Vague asistían a la proyección de Viaggio in Italia de Roberto Rossellini y descubrían que era posible hacer cine con muy pocos medios». El neorrealismo surge entonces no solo como una cuestión de temas (los pobres en las calles). «En el cine, en cambio, el neorrealismo no solo se opuso a una serie de películas que se parecían demasiado al teatro o que se alejaban de la vida cotidiana, sino que vino a mostrar el carácter inconexo y errático del acontecimiento, su resistencia a ser inscripto en esquemas preconcebidos. Un registro de las superficies (las calles, los gestos, los cuerpos, los desplazamientos) en un momento en que las ruinas no autorizaban ningún realismo convencional o consolatorio» (12-13). Debemos mencionar que el Nuevo Cine Argentino ha sido comparado en numerosos estudios con el Neorrealismo Italiano y con la Nouvelle Vague, por sus características formales.

5 Hartsfeld, en su análisis de la cultura de la pobreza nos recuerda que «el comercio minorista de cannabis, la prostitución ocasional de personas pobres es un recurso ingrato, pero parcialmente asumido porque así lo dicta la ley de bronce de la supervivencia» (61). 
te: «The prostitute and the client bring to the prostitution contract certain expectations about the mechanics of the contract and the tasks to be performed. They bring with them their relation to their bodies and to the bodies of the other - each constrained by a historical configuration in and throughout modern liberal democracies» (112).

Aunque Paula ignore este contrato y no siga las reglas de juego, ella quiere el dinero, no ofrece su cuerpo ni respeta lo acordado con sus clientes. Un ejemplo de esta «desobediencia» es el de la última escena con Raúl, el español, quien le paga dos veces la tarifa normal para quedarse con ella la noche completa, pero Paula, una vez que termina la relación sexual, trata de escapar, y no respeta lo estipulado.

Sin embargo, aunque los personajes alcancen algún tipo de nivel de conciencia, Elsa termina arrojando la moneda a la Fontana de Trevi, como dejándole al azar su destino. Andrés continúa moviéndose sobre sus patinetas, buscando clientes, y Reny, en un intento casi suicida, mira cómo se mezcla su propia sangre con el agua de la bañera. Afuera, la ciudad "como un monstruo" extiende sus tentáculos, impasiva, como impasivas son las criaturas que se mueven alrededor en esta oscuridad, en sus profundas soledades. No hay bien ni mal porque no hay ley ni prohibición ni padre ni autoridad. La naturaleza de los personajes, su ensamblaje urbano, se caracteriza por la falta de escrúpulos frente a las acciones cotidianas. Robar, vender los cuerpos, usar drogas, traficar medicamentos, trabajar en trabajos mal pagados, forman parte de las estrategias de supervivencia que parecen darle sentido a sus vidas. ${ }^{6}$

De algún modo y para concluir podríamos afirmar que este tipo de cine crea una estética del abandono que explora las vidas desencantadas de un grupo de individuos, quienes empujados a los márgenes de las instituciones sociales y los discursos politicos, han sido excluidos del espacio social comunitario. Fuera del grupo se mueven solos, sin esperanzas, confundidos, a través de la ciudad, de día y de noche, buscando una suerte de redención.

\section{REFERENCIAS}

Aguilar, Gonzalo. «Renuncia y libertad. Sobre una película de Lisandro Alonso». Mil palabras. letras y artes en revista 2 (2001). 11-13. Medio impreso.

Aguilar, Roberto. «La ciudad, esa cloaca inmunda». El Comercio. Quito, 2000. Medio impreso.

Augé. Marc. «Espacio y alteridad». Revista de Occidente 140 (1993). 13-34. Medio impreso.

Barky, Sandra Lee. Feminity and Domination. Studies in the Phenomenology of Oppression. New York: Routledge, 1990. Medio impreso.

Baudrillard, Jean. "Violencia descarnada. El odio». Pantalla total. Barcelona: Anagrama, 2000. 107-111. Medio impreso.

6 Para Rosi Brandotti: «El nómade no representa solamente la falta de un hogar ni el desplazamiento compulsivo; es más bien una figuración del tipo de sujeto que ha renunciado a toda idea, deseo de lo establecido. Esta figuración expresa el deseo de una identidad hecha de transiciones» (58). 
Bernardes, Horacio; Diego Lerer y Sergio Wolf (Eds.). Nuevo cine argentino. Temas, autores y estilos de una renovación. Buenos Aires: Fipresci Argentina, 2001. Medio impreso.

Brandotti, Rosi. Sujetos nómades. Buenos Aires: Paidós, 2000. Medio impreso.

Careaga, Gabriel. Erotismo, violencia y política en el cine. México: Joaquín Mortiz, 1981. Medio impreso.

Carpenter, Belinda J. Re-Thinking Prostitution. Feminism, Sex and the Self. New York: Peter Lang, 2000. Medio impreso.

Casey, Edward S. «How to Get from Space to Place in a Fairly Short Stretch of Time: Phenomenological Prolegomena». Senses of Place. Feld, Steven y Keith H. Basso (eds.). Santa Fe, New Mexico: School of American Research Advanced Seminar Series, 1996. 13-53. Medio impreso.

Filc, Judith. «Textos y fronteras urbanas: palabra e identidad en la Buenos Aires contemporánea». Revista Iberoamericana. 69/202 (2003). 183-184. Medio impreso.

García Canclini, Néstor. Imaginarios urbanos. Buenos Aires: Eudeba, 1999. Medio impreso.

Grimson, Alejandro y Gabriel Kessler. On Argentina and the Southern Cone. Neoliberalism and National Imaginations. New York: Routledge, 2005. Medio impreso.

Grosz, Elizabeth. «Bodies-Cities». Feminist Theory and the Body, a Reader. Janet Price and Margrit Shildrick (eds.). New York: Routledge, 1999. 381-387. Medio impreso.

Hatzfeld, Marc. La cultura de los suburbios. Barcelona: Laertes, 2007. Medio impreso.

Hoy y mañana. Chomski, Alejandro, dir. Act. Antonella Costa, Carlos Lipsic, Romina Ricci. DVD. Aldebaran Films, 2003. Medio fílmico.

Lacan, Jacques. Seminario II. Cuatro conceptos fundamentales del psicoanálisis. Buenos Aires: Paidós, 1999. Medio impreso.

León, Christian. El Cine de la Marginalidad. Realismo sucio y violencia urbana. Quito: Univ. Andina Simón Bolívar, Ediciones Abya-Yala y Corporación Editora Nacional, 2005. Medio impreso.

Lyotard, Jean-François. La condición postmoderna. Madrid: Cátedra, 1987. Medio impreso.

Monteagudo, Luciano. «El sexo en la vidriera de los cajeros». Página 12, Jueves 13 de junio de 2002: Espectáculos. Sitio Web. Fecha de ingreso: 25 de Julio de 2007.

Un día de suerte. Gugliotta, Sandra, dir. Act. Valentina Bassi, Fernán Mirás, Darío Vittori. DVD. Cinema tropical, 2002. Medio Fílmico.

Vagón fumador. Chen, Verónica, dir. Act. Leonardo Brezicki, Cecilia Bengolea. DVD. Primer Plano Film Group, 2001. Medio fílmico.

Wolf, Sergio. «The Aesthetics of the New Argentine Cinema: The Map is the Territory». New Argentine Cinema. Themes, Auteurs and Trends of Innovation. Bernardes, Horacio; Diego Lerer y Sergio Wolf (eds.). Buenos Aires: Fipresci Argentina, 2001. 2943. Medio impreso.

Recepción: 11 de enero de 2010 Aceptación: 29 de enero de 2010 